\section{Open heart surgery with deep hypothermic cardiopulmonary bypass and more than 90 minutes of aortic cross clamp time in 10 small dogs}

\author{
Kippei Mihara, ${ }^{1}$ Isamu Kanemoto, ${ }^{1}$ \\ Keiichi Sato, ${ }^{1}$ Takuya Mori,1,2 \\ Hirokazu Abe, 1 Seiya Niimi, ${ }^{1}$ \\ Koji Yamada,1 Kenji Ohira, 1 \\ Takanori Andou, 1,3 Atsushi Hirakawa4 \\ 1Chayagasaka Animal Hospital, Chikusa, \\ Nagoya, Aichi; '2Department of \\ Cardiovascular Surgery, Juntendo \\ University Graduate School of Medicine, \\ Tokyo; ${ }^{3}$ Heart-Will Animal Hospital, \\ Fukuoka, 4Pet Clinic Hallelujah, Fukuoka, \\ Japan
}

\begin{abstract}
No previous reports have described cardiopulmonary bypass (CPB) techniques involving long aortic cross clamp (ACC) times in small-breed dogs. We previously described open heart surgery under deep hypothermic CPB in small and toy dogs with an approximate ACC time limit of 1 hour, given the low success rate beyond 90 minutes of ACC time. Herein, we describe improvements in cardiac anesthesia, CPB, and cardioplegia that led to a high success rate of open heart surgery with a long ACC time in small dogs. Ten small-breed dogs with severe mitral regurgitation were subjected to mitral valve plasty that necessitated cardiopulmonary bypass (CPB) beyond $90 \mathrm{~min}$ utes of ACC time. In the present study, all dogs survived surgery; 7 survived to discharge. In other words, we achieved a high success rate of $70 \%$ with mitral valve plasty beyond 90 minutes of ACC time (mean, 105.1 minutes: range, 90-117 minutes). For small dogs, successful open heart surgery with a long ACC time may require cardiac balanced anesthesia, $\mathrm{CPB}$ with increased drainage and, importantly, thorough cardioplegia without hemodilution.
\end{abstract}

\section{Introduction}

Cardiopulmonary bypass (CPB) in humans or non-human animals with low body weights is associated with challenging factors such as hemodilution, cardioplegia, and anesthesia.1,2 However, few reports have described CPB techniques in small- or toy-breed dogs, 3,4 despite some reports of CPB techniques in larger dogs. ${ }^{5-}$ 8 In addition, no reports have described the use of $\mathrm{CPB}$ techniques involving long aortic cross clamp (ACC) times in small dogs, even though the complete repair of complex intracardiac lesions requires a long ACC time and extensive CPB techniques. ${ }^{9}$ Ideally, however, in dogs the ACC time should not exceed 90 minutes; longer times have been associated with a low success rate. ${ }^{10}$ In our previous report, we described open heart surgery under deep hypothermic CPB in small and toy dogs, with a limit of approximately 1 hour of ACC time. ${ }^{3}$ At that time, our success rate was low with regard to open heart surgery beyond 90 minutes of ACC time in small dogs. However, in this paper, we describe more recent improvements in our cardiac anesthesia, CPB, and cardioplegic techniques that have allowed us to achieve a high success rate for open heart surgery beyond 90 minutes of ACC time in small dogs.

\section{Materials and Methods}

Between September 2013 and May 2014, 10 small dogs (3 Shih Tzus, 2 Chihuahuas, 2 miniature Schnauzers, 1 Maltese, 1 Pomeranian, and 1 Cavalier King Charles Spaniel) were subjected to mitral valve plasty (MVP) for severe (American College of Veterinary Internal Medicine stage C-D) mitral regurgitation (MR) that necessitated CPB with an ACC time $>90$ minutes. The dogs had a mean age of 9.3 years (range, 7.3-10.8 years) and a mean body weight at surgery of $5.1 \mathrm{~kg}$ (range, 2.9-8.7 kg; Table 1). Basic MVP techniques comprised chordal reconstruction (CR) using expanded polytetrafluoroethylene (ePTFE) sutures in both mitral valve leaflets, and semicircular suture annuloplasty (AP) using polypropylene (Proline) sutures in the posterior valve ring. Additional MVP techniques were used in all cases with valvuloplasty (VP) via a method involving direct suture of cusps in the posterior leaflet.11 The basic CPB techniques were reported in a previous study; 3 however, some techniques were improved as described below.

\section{Anesthesia}

Dogs were premedicated with atropine sulfate $(25 \mu \mathrm{g} / \mathrm{kg}$ intramuscularly [IM]), ketamine hydrochloride $(2.5 \mathrm{mg} / \mathrm{kg}$ intravenously [IV]), fentanyl hydrochloride ( $5 \mu \mathrm{g} / \mathrm{kg}$ IV), and midazolam hydrochloride $(0.2 \mu \mathrm{g} / \mathrm{kg}$ IV) before inducing anesthesia with thiamylal sodium $(12.5 \mathrm{mg} / \mathrm{kg}$ IV to effect) or alfaxalone $(2 \mathrm{mg} / \mathrm{kg}$ IV to effect). Anesthesia depth was maintained with $0.5-1.5 \%$ isoflurane in oxygen, fentanyl hydrochloride $(10 \mu \mathrm{g} / \mathrm{kg} / \mathrm{h}$ continuous rate infusion [CRI]), and/or alfaxalone (0.02 $\mathrm{mg} / \mathrm{kg} / \mathrm{min} \mathrm{CRI}$ ) with intermittent pancronium bromide $(0.06 \mathrm{mg} / \mathrm{kg} \mathrm{IV})$ or rocuronium $(0.5$ $\mathrm{mg} / \mathrm{kg} \mathrm{IV}$, followed by $6 \mu \mathrm{g} / \mathrm{kg} / \mathrm{min}$ CRI) accord-
Correspondence: Isamu Kanemoto, Chayagasaka Animal Hospital, 1-1-5 Shinnishi, Chikusa, Nagoya, Aichi, 464-0003 Japan.

Tel.: +81.527.731.866 - Fax: +81.527.737.488

E-mail: kanemoto@ta2.so-net.ne.jp

Key words: small dog, long aortic cross clamp time, mitral valve plasty, cardiopulmonary bypass, hypothermia.

Acknowledgements: we would like to thank Editage (www.editage.jp) for English language editing.

Contributions: the authors contributed equally to this manuscript.

Conflict of interest: the authors declare no conflict of interest.

Received for publication: 1 February 2016 Accepted for publication: 26 April 2016.

This work is licensed under a Creative Commons Attribution NonCommercial 4.0 License (CC BYNC 4.0).

(C) Copyright K. Mihara et al., 2017

Licensee PAGEPress srl, Italy

Veterinary Science Development 2017; 7:6442

doi:10.4081/vsd.2017.6442

ing to the anesthetic effect. Hypothermia was slowly induced to an esophageal temperature (ET) of $20-25^{\circ} \mathrm{C}$ via blood cooling with a heatexchanger. Immediately before ACC release, blood rewarming was initiated slowly at a rate of $5^{\circ} \mathrm{C}$ to an ET of $37^{\circ} \mathrm{C}$ with a heat-exchanger.

\section{Cardiopulmonary bypass}

A venous drainage cannula (Toyobo TWN812, Toyobo Co., Tokyo, Japan) modified to include 4-5 side holes at the tip (Figure 1) and an arterial cannula were inserted into the right atrium via the left jugular vein and left carotid artery, respectively. These instruments were connected to the CPB open circuit (total priming volume, $188 \mathrm{~mL}$ ), which comprised a hard reservoir and membrane oxygenator (Terumo Baby RX-05; Terumo Co., Tokyo, Japan) combined with a heat-exchanger (Figure 2).

Unoxygenated blood was drained by gravity through the venous cannula into the reservoir.

A roller pump returned oxygenated blood to the carotid arterial cannula through the membrane oxygenator and heat-exchanger. The priming solution comprised acetated Ringer solution (200 mL), 7\% sodium bicarbonate (15 mL), mannitol $(15 \mathrm{~mL})$, cefazolin $(200 \mathrm{mg})$, and crossmatched donor blood $(60-100 \mathrm{~mL})$ added to maintain a hematocrit (Ht) of approximately $20 \%$.

\section{Cardioplegia}

After ACC, cold $\left(4^{\circ} \mathrm{C}\right)$ St. Thomas' II cardio- 


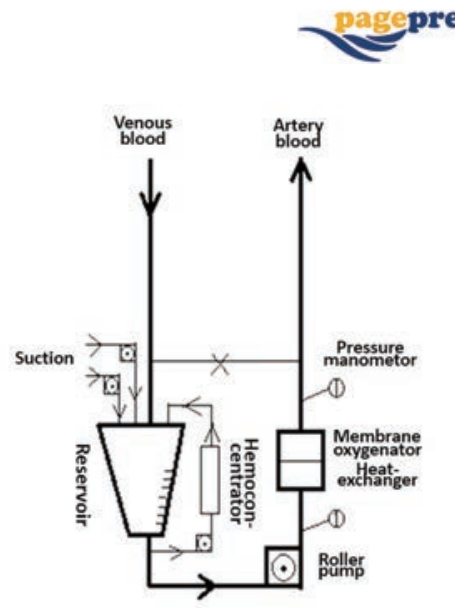

plegic solution (Miotector, Mochida Pharmaceutical Co, Tokyo, Japan), which was initially added with KCL to increase the $\mathrm{K}^{+}$ concentration from $16 \mathrm{mEq}$ to $20 \mathrm{mEq}$, was immediately injected in an antegrade manner at $100-120 \mathrm{mmHg}$ of pressure through an aortic root cannula via syringe; this was repeated every 20 minutes or when an action potential occurred on the electrocardiogram (ECG). The initial dose was $20 \mathrm{ml} / \mathrm{kg}$; all subsequent doses were $10 \mathrm{ml} / \mathrm{kg}$, and all were ultrafiltered at the reservoir to approximately the same volume using a hemoconcentrator (MAQUET BC 20 plus, Maquet Japan Co., Tokyo, Japan) parallel to the CPB circuit (Figure 2).

\section{Results}

Open heart surgeries were performed with a mean ACC time of 105.1 minutes (range, 90117 minutes), mean lowest ET of $22^{\circ} \mathrm{C}$ (range, 20.3-25. $2^{\circ} \mathrm{C}$ ), and mean total pump time of 147.5 minutes (range, 117-190 minutes). During ACC, the mean pump flow was 64.3 $\mathrm{mL} / \mathrm{kg} / \mathrm{min}$ (range, 46.9-80.9 $\mathrm{mL} / \mathrm{kg} / \mathrm{min}$ ), mean aortic pressure was $63.5 \mathrm{mmHg}$ (range, $51.7-75.8 \mathrm{mmHg}$ ), and mean urine volume was $5.8 \mathrm{~mL} / \mathrm{kg} / \mathrm{h}$ (1.8-16.6 mL/kg/h; Table 2). The mean Ht before CPB was $31.4 \%$ (range, 16.9 47.6\%); this was reduced via hemodilution during $\mathrm{CPB}$ to a mean value of $22 \%$ (range, 18.4-27.9\%). The mean $\mathrm{Ht}$ after CPB was $28.1 \%$ (21.6-33.5\%). The mean elapsed time from the beginning of blood cooling to an ET of $22^{\circ} \mathrm{C}$ was 44.2 minutes (range, 30-55 minutes), and the mean elapsed time for rewarming to an ET of $37^{\circ} \mathrm{C}$ was 41.2 minutes (range, 25-65 minutes). The mean time from the end of the operation to extubation was 197.1 minutes (range, 62385 minutes; Table 3). All dogs survived surgery, and 7 survived to discharge (success rate,

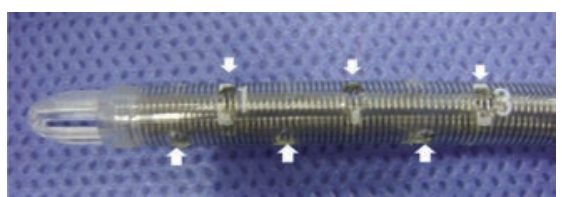

Figure 1. A venous drainage cannula (Toyobo TWN8-12, Toyobo Co. Tokyo, Japan), altered by the addition of 4-5 hand-made side holes at the tip.
Figure 2. Cardiopulmonary bypass (CPB) open circuit (total priming volume, 188 $\mathrm{ml}$ ), comprising a hard reservoir, a roller pump, and a membrane oxygenator (Terumo Baby RX-05; Terumo Co., Tokyo, Japan) combined with a heat-exchanger. Left jugular vein blood is drained by gravity through the venous cannula into the reservoir. A roller pump returns oxygenated blood to the carotid arterial cannula through the membrane oxygenator and heat-exchanger. In addition, the hemoconcentrator (Maquet BC 20 plus, Maquet Japan Co., Tokyo, Japan) is parallel to the CPB circuit at the reservoir.

Table 1. Cases, intracardiac surgeries, and results.

\begin{tabular}{|c|c|c|c|c|c|c|c|c|}
\hline Case & Breed & BW, kg & Age, $\mathbf{y}$ & Sex & Diagnosis & Operation & Result & Cause \\
\hline 1 & KC Cavalier & 6 & 10.2 & q & MR & MVP & Alive & - \\
\hline 2 & Pomeranian & 4.26 & 8 & o & MR & MVP & Alive & - \\
\hline 3 & M schnauzer & 4.1 & 9 & 우 & MR & MVP & Alive & - \\
\hline 4 & Shih Tzu & 8.7 & 10.3 & $\hat{0}$ & MR & MVP & Dead (2 d later) & PE \\
\hline 5 & Chihuahua & 3 & 9.2 & q & MR & MVP & Alive & - \\
\hline 6 & Chihuahua & 3 & 7.3 & q & MR & MVP & Dead (14 h later) & ARF \\
\hline 7 & Shih Tzu & 8.5 & 10 & 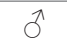 & MR & MVP & Dead (23 h later) & ARF \\
\hline 8 & Shih Tzu & 5.2 & 10 & o & MR & MVP & Alive & - \\
\hline 9 & M schnauzer & 5.3 & 8 & q & MR & MVP & Alive & - \\
\hline 10 & Maltese & 2.9 & 10.8 & $\hat{0}$ & MR & MVP & Alive & - \\
\hline Mean & & 5.1 & 9.3 & & & & & \\
\hline
\end{tabular}

MR, mitral regurgitation; MVP, mitral valve plasty PE, pulmonary edema

Table 2. Cardiopulmonary bypass parameters.

\begin{tabular}{|c|c|c|c|c|c|c|}
\hline Case & $\begin{array}{l}\text { ACC time, } \\
\text { min }\end{array}$ & $\begin{array}{l}\text { Lowest ET, } \\
{ }^{\circ} \mathrm{C}\end{array}$ & $\begin{array}{l}\text { Pump time } \\
\text { (min) }\end{array}$ & $\begin{array}{l}\text { MPF during ACC } \\
\text { (mL/kg/min) }\end{array}$ & $\begin{array}{l}\text { MAP during ACC } \\
(\mathrm{mmHg})\end{array}$ & $\begin{array}{l}\text { UV during ACC } \\
\text { (mL/kg/h) }\end{array}$ \\
\hline 1 & 105 & 20.3 & 145 & 47.9 & 75.8 & 7.2 \\
\hline 2 & 99 & 23.8 & 120 & 46.9 & 66.2 & 3.2 \\
\hline 3 & 92 & 20.8 & 117 & 69.7 & 73.5 & 16.6 \\
\hline 4 & 113 & 23.9 & 163 & 60.5 & 65.1 & 2.6 \\
\hline 5 & 108 & 25.2 & 152 & 80.9 & 69.1 & 2.4 \\
\hline 6 & 106 & 21 & 140 & 77.4 & 58.6 & 1.8 \\
\hline 7 & 110 & 20.5 & 190 & 55.4 & 51.7 & 3.7 \\
\hline 8 & 90 & 22.5 & 122 & 80 & 66.4 & 9 \\
\hline 9 & 117 & 20.5 & 190 & 49.7 & 54.6 & 5.7 \\
\hline 10 & 111 & 21 & 136 & 74.9 & 54.1 & 5.8 \\
\hline Mean & 105.1 & 22 & 147.5 & 64.3 & 63.5 & 5.8 \\
\hline
\end{tabular}


Table 3. Other cardiopulmonary bypass parameters.

\begin{tabular}{lcccccc} 
Case & Before CPB & $\begin{array}{c}\text { HTT } \% \\
\text { During CPB }\end{array}$ & After CPB & Cooling time (min) & Rewarming time (min) & Extubation time (min) \\
1 & 21.2 & 19.1 & 29.6 & 44 & 42 & 240 \\
2 & 16.9 & 19.8 & $?$ & $(25)$ & $(15)$ & 218 \\
\hline 3 & 24.8 & 18.4 & 32 & 36 & 25 & 62 \\
4 & $?$ & $?$ & $?$ & $(35)$ & $(40)$ & 340 \\
\hline 5 & 47.6 & 22.9 & 28.2 & $(28)$ & 50 & 130 \\
6 & 34.4 & 22.6 & 25.6 & 45 & 35 & $\times$ \\
\hline 7 & 42.6 & 27.9 & 33.5 & 55 & $(30)$ & 70 \\
8 & 35.9 & 20.9 & 26.5 & $(35)$ & 65 & 385 \\
\hline 9 & 21.9 & 22.6 & 21.6 & 55 & 30 & 132 \\
\hline 10 & 37 & 23.4 & $?$ & 30 & 41.2 & 197.1 \\
\hline Mean & 31.4 & 22 & 28.1 & 44.2 & & \\
\hline
\end{tabular}

$\mathrm{CPB}$ : cardiopulmonary bypass, Ht: hematocrit, ET: esophageal temperature. Cooling time: elapsed time from beginning of CPB to ET of $22^{\circ} \mathrm{C}$. Rewarming time: time required for rewarming to ET of $37^{\circ} \mathrm{C}$. Extubation time: elapsed time from the end of surgery to extubation. ?: unclear, ( ): inaccurate, $\times$ : immeasurable.

70\%). Dog No. 4 died 2 days after surgery because of pulmonary edema. Dogs No. 6 and 7 were euthanized 14 and 23 hours after surgery, respectively, because of acute renal failure (ARF; Table 1).

\section{Discussion}

A long ACC time and improved CPB techniques are needed to ensure the complete repair of complex intracardiac lesions. ${ }^{9}$ In our cases, which were affected by severe MR lesions involving both valve leaflets, MVP surgery required an ACC time $>90$ minutes and a long CPB time. In addition, techniques that combined MVP with multiple (4-8) CR, semicircular suture AP, and VP of multiple (2-4) valve cusp direct sutures were required. ${ }^{11}$ As a result, the MVP surgeries in our study required a mean ACC time of 105 minutes. However, our overall success rate was $70 \%$.

During heart transplantation with severe congestive cardiac failure, anesthesia is carefully administered to ensure hemodynamic stability. ${ }^{12}$ Anesthesia in cases of severe MR with congestive cardiac failure also requires the same level of attention. 13 Therefore, premedication, induction, and maintenance were recently changed from a deep state to a milder state of anesthesia using balanced anesthesia to ensure good hemodynamic maintenance (e.g., aortic pressure, urine volume). Improvements in anesthesia may have led to delayed CPB initiation with a relatively shorter CPB time compared to our previous study, regardless of the longer ACC time (mean pump time, 147.5 minutes with a mean ACC time of 105.1 minutes). ${ }^{3}$ Increased drainage flow is required to increase the pump flow. ${ }^{14}$ In the present study, an improvement made to the venous drainage cannula, involving the addi- tion of 4-5 side holes at the tip to increase the efficiency and drainage flow, led to an increase in pump flow during ACC from a low to moderate flow. ${ }^{15}$ In addition, the location of the drain tube tip was adjusted at the middle site in the right atrium via transesophageal or transthoracic echocardiography. Moreover, excessive slinging of the pericardial hammock was avoided to prevent kinking of the posterior vena cava. In the present study, we found that with mild anesthesia, the mean pump flow during ACC increased, and the aortic pressure and urine volume during ACC both increased interdependently in comparison to the previous study. ${ }^{3}$ Furthermore, in this study, the dose of cold St. Thomas' II solution ${ }^{16}$ was increased 2fold relative to our previously reported volume, ${ }^{3}$ and was repeated every 20 minutes 17 or when an action potential occurred on the ECG monitor. Accordingly, the recovery of myocardial contractile strength and weaning from CPB occurred more rapidly, regardless of the long ACC. The hemoconcentrator coped well with excessive hemodilution due to an increase in cardioplegic solution, ${ }^{18}$ and a postprocedural increase was observed in the mean Ht relative to the level during $\mathrm{CPB}$. In the future, bloodless CPB, involving blood or hotshot cardioplegia and a small circuit, may be more useful in small and toy dogs. We lost 3 dogs during the present study, all of which were among the 5 dogs (No. 4-8) that underwent surgery at a satellite hospital, which was managed by an inexperienced intensive care unit staff. Dog No. 4 died of pulmonary edema with an unknown etiology 2 days after surgery. As this dog had been successfully extubated at 340 minutes after surgery, CPB did not appear to be the primary cause of pulmonary edema. For dog No. 6, which died of ARF, re-thoracotomy was performed at 5 hours, 20 minutes after surgery because of sustained blood leakage in the chest cavity, which might have led to olig- uria and anuria consequent to low output syndrome (LOS). Despite the large urine volume during ACC (3.7 mL/kg/h) and reduced bleeding in the thoracic cavity after chest closure relative to dog No. 6 , dog No. 7 , which also died of ARF, appeared to develop LOS as a result of poor cardioplegia and/or postoperative management. We note that in contrast to a report involving human conditions, our 2 cases did not appear to be related to hemodilution during CPB. 19

\section{Conclusions}

Cardiac balanced anesthesia for hemodynamic stability, CPB with increased drainage to ensure moderate pump flow during ACC and, especially, thorough cardioplegia without hemodilution appear to be essential to a high success rate following open heart surgery with a long ACC time in small dogs.

\section{References}

1. Gaynor JW, Kern FH, Greeley WJ, Ungerleider RM. Management of cardiopulmonary bypass in infants and children. In: Baue AE, Geha AS, Lask H, et al, eds. Glenn's thoracic and cardiovascular surgery. 6th ed. Stamford, CT: Appleton \& Lange; 1996. p. 1023-34.

2. Kern FH, Greeley WJ, Ungerleider RM. Cardiopulmonary bypass, In: Nichols DG, Cameron DE, Greeley WJ, et al, eds. Critical heart disease in infants and children. St. Louis: Mosby; 1995. p. 497-530.

3. Kanemoto I, Taguchi D, Yokoyama S, et al. Open heart surgery with deep hypother- 
mia and cardiopulmonary bypass in small and toy dogs. Vet Surg 2010;39:674-9.

4. Lew LT, Fowler JD, Egger CM, et al. Deep hypothermic low flow cardiopulmonary bypass in small dogs. Vet Surg 1997;26: 281-9.

5. Klement P, del Nido PJ, Mickleborough L, et al. Technique and postoperative management for successful cardiopulmonary bypass and open-heart surgery in dogs. $\mathrm{J}$ Am Vet Med Assoc 1987;190:869-74.

6. Holmberg D. Extracorporeal circulatory support. In: Slatter D, ed. Textbook of small animal surgery. 2nd ed. Philadelphia: WB Saunders; 1993. p. 918-22.

7. Orton EC. Cardiac surgery. In: Slatter D, ed. Textbook of small animal surgery. 3rd edition. Philadelphia: WB Saunders; 2003. p. $955-86$.

8. Komtebeddle J, Ilkiw JE, Follette DM, et al. Resection of subvalvular aortic stenosis. Surgical and perioperative management in seven dogs. Vet Surg 1993;22:419-30.

9. Kirklin JW. The science of cardiac surgery. Eur J Cardiothorac Surg 1990:4;63-71.

10. Orton C. Cardiopulmonary bypass. In:
Monnet E, ed. Small animal soft tissue surgery. Ames: Wiley Blackwell; 2013. p. 78691.

11. Kanemoto I, Taguchi D, Mihara K, et al. Long-term survival of two dogs after mitral valve plasty. Vet Sci Dev 2016;7:6335.

12. Quinlan JJ, Murray AW, Casta A. Anesthesia for heart, lung, and heart-lung transplantation. In: Kaplan JA, Reich DL, Savino JS, eds. Kaplan's cardiac anesthesia. 6th ed. St Louis: Saunders; 2011. p. 737-54.

13. Nussmeier NA, Sarwar MF, Searles BE, et al. Anesthesia for cardiac surgical procedures. In: Miller RD, Eriksson LI, Fleisher LA, et al, eds. Miller's anesthesia. 8th ed. Philadelphia: Elsevier Saunders; 2015. p. 2007-95.

14. Becher GA. Venous hemodynamics. In: Becher GA, ed. Venous return. New York; Grune \& Stratton; 1956. p. 54-70.

15. Hori Y, Saitoh R, Touei D, et al. Comparison of blood removal catheters for extracorporeal circulation in low body weight animals. Adv Anim Cardiol 2012;45:1-7.
16. Jynge P, Hearse DJ, Feuvray D, et al. The St. Thomas' hospital cardioplegic solution: a characterization in two species. Scand J Thorac Cardiovasc Surg Suppl 1981;30:128.

17. Slater MS, Komanopalli CB, Song H. Myocardial protection. In: Gravlee GP, Davis RF, Stammers AH, Ungerleider RM, eds. Cardiopulmonary bypass: principles and practice. 3rd ed. Philadelphia: Lippincott Williams \& Wilkins; 2008. p. 172-89.

18. Sutton RG, Rothenberg DM. Ultrafiltration and dialysis. In: Gravlee GP, Davis RF, Stammers AH, Ungerleider RM, eds. Cardiopulmonary bypass: principles and practice. 3rd edition. Philadelphia: Lippincott Williams \& Wilkins; 2008. p. 114-27.

19. Karkouti K, Beattie WS, Wijeysundera DN, et al. Hemodilution during cardiopulmonary bypass is an independent risk factor for acute renal failure in adult cardiac surgery. J Thorac Cardiovas Surg 2005;129:391-400. 